\title{
Forum
}

\section{Online teaching: a reflection}

\author{
Sam Baddeley \\ Independent Scholar
}

Key words: remote education, online teaching, formative assessment

\section{Introduction}

This article, written at the start of April 2021, is a personal reflection on what has and hasn't worked in remote/online education. I have drawn on my own experience of teaching over the course of the past year, observations of classroom practice I have undertaken as a mentor and middle leader with responsibility for teaching and learning in my school, and conversations I have had with colleagues in my school and elsewhere; it is, therefore, highly anecdotal, and the reader is asked to bear in mind the fact that, like many others, my journey into online teaching was enforced by the closure of schools during the first nationwide lockdown in March 2020. My core aim during both lockdowns was to provide for my students the best experience possible until such a time as we could all return to the physical classroom. As it became clear towards the end of 2020 and the start of 2021 that we were going to need to return to remote education, I began to think more deeply about the strategies I was employing in my online teaching, how effective they were for my students, and what I might do to maximise their learning experience and outcomes.

What follows is mostly a description of my experience; but I also offer some suggestions as to how teachers might wish to approach remote/online teaching should they need to do so again, and what we might want to take forward from our remote/online experience into our in-person teaching.

A note on terminology: I will be using the definition for remote education provided by Ofsted: '[A]ny learning that happens outside of the classroom, with the teacher not present in the same location as the students. This includes both digital and non-digital remote solutions' (Ofsted, 2021a). I am primarily concerned in this article with 'online education', which I define as a subcategory of remote education, that is to say, digital remote solutions.

\section{The context}

I teach in an independent, full-boarding school for boys (years 9-13). The school is academically selective; indeed, its most recent (regulatory compliance) ISI (Independent Schools' Inspectorate) report of 2018 states that 'the ability profile of the students is well above the national average' and the integrated inspection report of

Author of correspondence: Sam Baddeley, E-mail: sambaddeley87@gmail.com Cite this article: Baddeley S (2021). Online teaching: a reflection. Journal of Classics Teaching, 22, 109-116. https://doi.org/10.1017/S2058631021000246
2015 notes that 'the students' achievements and learning are exceptional'. The proportion of students who are identified as having special educational needs and / or disabilities is low: 78 out of 691 students in the most recent inspection, of whom 23 were receiving additional support; of those for whom English was an additional language in 2018 (135 out of 691), only eight were receiving formal support. The number of students studying classical subjects is high. We offer Latin and Greek in Years 9-13.

I teach both classical languages and a Year 9 English course which contains some classical literature in translation; I also have a whole-school teaching-and-learning role which involves leading staff induction and supporting colleagues in the development of their classroom practice. From March-April 2020, my role began to encompass online learning, and I managed a team of colleagues whose job it was to train staff towards the end of the summer and the start of the autumn term in the use of Microsoft Teams and other applications within the Microsoft 365 package. I also devised and managed the responses to several surveys (staff and student voice) to determine how we might be able to improve our online teaching. I am digitally literate but I am by no means an expert, and I have relied very much on more able colleagues to support me and our school in developing this area of our pedagogy.

As a school we have been very fortunate, in that we were set up for online learning before the pandemic hit: all students in Years 9-12 are equipped with the same device (a Microsoft Surface Pro) ${ }^{1}$. I cannot stress enough what a difference that has made to our experience, and I am painfully aware of how much more challenging it has been for students and teachers in other contexts. Limited or no access to technology is one of the central obstacles to effective remote education, as noted by the Education Endowment Foundation (2021), and sadly there is no doubt that educational inequality has increased across the globe during and as a result of the pandemic (as noted in The Economist in July 2020). Even in institutions in which all students have devices, a lack of uniformity of device can cause difficulties and frustrations. I myself have encountered this difficulty with my Year 13 sets: the fact that not all of my students are able to 'ink' (i.e. write on) their devices (as most pupils in that year group in my school have a device without a touchscreen) is something which I have, at times, forgotten. I have therefore set various digital tasks (such as asking my Year 13 Latin literature set to draw a map of the harbour at Syracuse as described in Cicero's In Verrem) which have then required last-minute adaptation. 
When the pandemic first hit, my line manager and I devised a curriculum for the summer term of 2020 which involved the teaching of $50 \%$ of lessons as 'live' (i.e. synchronous), with $50 \%$ designated for what we termed 'non-contact' (i.e. asynchronous) work. For Years 9 and 10, we abandoned homework and subsumed it into the timetable (i.e. into the asynchronous periods, known to us as 'non-contact' periods), and there were necessary modifications for exam years (Year 11 and Year 13). Recorded lessons were not routinely used as part of our curriculum.

Not all schools in the independent sector chose to reduce their timetable at this stage. Our reasoning was as follows:

a) Although we were equipped with effective hardware and software, the reality is that we were not a very technologicallyminded school; many colleagues and students had barely used their Surfaces for anything other than email and typing Word documents. As a result, we were concerned about the effects on student and teacher wellbeing of a sudden increase in screen time.

b) We taught one week of online lessons before breaking up for the Easter holiday; I then surveyed the staff and students to get a sense of how they had found it. The results of that survey (which resonated with my own experience) suggested strongly that lesson planning was going to take much longer than usual: colleagues' resources were sometimes not available in a digital format and/or they needed to be adapted, and there was widespread uncertainty as to which sorts of tasks could be adapted to the digital environment. We felt that colleagues would fare better if given fewer lessons to teach, that the quality of their lessons would improve, and that our students - being, in the main, self-motivated - would benefit from periods of independent study.

c) We felt it important that students should have enough time to spend with their families: our standard curriculum model is designed for a situation in which they are all living in school, and we recognised that such a model would not necessarily work when students were living at home.

d) Teaching colleagues with children were clearly going to find it hard to balance homeschooling their own children and teaching a full timetable: we hoped that the flexibility provided by our system would benefit them, their families and their students.

e) The time difference for overseas students is such that those of our students who remained in the Far East due to Covid restrictions on travel were starting their first lesson of the day at 16.45 and finishing at midnight. The flexibility provided by our new timetable would allow colleagues to remove some afternoon live lessons, thereby giving these students the chance to get work done earlier in the day.

During the most recent lockdown, we have followed a modified version of this curriculum (there has been an increase in teaching time for some year groups and subjects).

\section{Acceptance}

Four things were clear from the start: lesson planning was going to take more time; I would get through less material in each lesson; some things (e.g. the exam skill of unseen translation) could not be done in the same way in an online context; and pastoral care was going to be a challenge. I believe that acceptance of these truths was crucial in allowing me to approach remote learning with a positive mindset.

\section{Doing things differently}

At the start of the pandemic, many teachers (myself included) were trying to transfer exactly what we do in the classroom into a digital environment. This was an emergency measure, and was never likely to work in the long term. Indeed, my PGCE mentee's lessons dramatically improved from the point at which he decided (and vocalised) that he needed to do things differently, that is, to abandon some of his regular approaches to lesson planning and delivery and to maximise the opportunities afforded by technology for new types of lessons. I too soon realised that certain things were not going to work as well as in the classroom (e.g. drama activities) but that new opportunities had arisen (many of them provided by the plethora of free online resources, videos, professional productions of plays, etc. towards which we were all directed). My general strategies have included the following:

- The use of new applications for assessment (see below).

- The use of collaborative online documents (the OneNote Collaboration Space, SharePoint documents, etc.).

- The use of modified strategies for question-and-answer episodes in lessons, including the use of the 'chat' function in Microsoft Teams (see below).

However, a note of caution: the 'learning' aspect of teaching and learning is too frequently ignored even in the physical classroom, and online teaching might lead even the most skilled practitioner into activity-driven planning. It is all too easy to get excited about a new application and contrive a way to get it into a lesson plan, or even design a lesson around it. I have tried to think hard about my lesson objectives and to allow these to guide my planning. I have taken to heart the general principle, as advocated by education adviser Mary Myatt (who has spoken of 'doing fewer things in greater depth' [2020]), that 'less is more'. I have also tried to think carefully about what I want my students to be thinking, rather than just doing, remembering Coe's advice that busy-ness can be a poor proxy for learning (2015). Lesson objectives, such as these:

By the end of the lesson, students will be able to

- explain how adjectival agreement works in Latin;

- give examples of ways in which participles are used in Greek;

- compare two translations of Ovid's myth of Arachne;

- identify instances of the technique of amplification in In Verrem 2.5.97 and explain how they contribute to his argument in this chapter.

... have been far more effective in terms of promoting good progress than those which focus on the digital means of achieving a task, such as these:

By the end of the lesson, students will have

- completed a Spiral quiz on adjectival agreement;

- written a comparison of two translations of Arachne in the Collaboration Space on OneNote and then peer-assessed each other's work;

- delivered a PowerPoint presentation on the use of participles in Greek;

- completed a commentary question on OneNote focusing on amplification in In Verrem 2.5.97. 
I have tried to be discerning in my use of applications (apps): selection of the right app(s) for each task has been crucial, as has restricting each class to a handful of necessary apps in order to allow them to become proficient in using them. I am concerned that my own interest in new technology could lead tasks to become more about the technology than the task itself (not least because of the increased risk with new apps of technical issues).

\section{Practicalities and expectations: sweat the small stuff}

In my experience, certain classical subjects (such as reading texts in the original language) require student and teacher to have a lot of books on the go at the same time. For a GCSE Latin literature lesson, my students will need a minimum of three things: a copy of the text for annotation with grammatical and literary notes, a place where they can write out a translation (unless provided by me in typed format in advance/after the lesson - my practice varies depending on the group), and a vocabulary list or dictionary (online or in hard copy). Most students have managed their online lessons with a single device, that is to say, with one screen. I have found that it is vital to think carefully about this as I plan my lessons, particularly as I enjoy the luxury of more than one screen at home (i.e. the screen on my device, and a second monitor plugged into it). When my students and I are annotating a passage describing the death of Priam, and I am presenting my screen so that they are able to see the annotations, where are the students writing their notes? Are they annotating their text on the same screen on which they are viewing my annotations? Can they split the screen or is it impossible for them to see my notes and annotate their own text at the same time? Should I ask them to print out (or offer to send to them) a hard copy of the text before we begin the process of literary analysis? Do I want them to abandon their own annotations and just focus on mine? These questions are far less important in the physical classroom - I can spot and thus deal with any issues immediately. But it can be very easy to give this no thought (or not enough thought) when teaching online. I have in general advised students (certainly in the sixth form) to have a hard copy of the text on which to write their own annotations, thus freeing up the screen as a vehicle for viewing our class notes. When planning my online courses (and indeed before each online lesson), I try to ask myself what the students will have in front of them and how the lesson will work for them in practical terms.

Allied with the above is the importance of setting out one's expectations again at the start of the remote-learning period; in effect, I treated each lockdown as the start of a new school year, and laid out my procedure for asking and answering questions (e.g. asking students to use the 'hands-up' function in Teams to ask a question, but expecting me to cold call when I ask questions), what I expected the students to have with them for their lessons (textbook, paper, pen), what I wanted them to do at the start of each lesson (e.g. switch mobile phones off and close all applications with the exception of OneNote and Teams), what to do in case of internet issues, and how and when to use the 'chat' function.

Finally, all students in all contexts need to know what they are studying, where the course is going, and what will be achieved over a period of time. I have found this to be particularly important for those for whom pre-learning / preparation in advance of a lesson is useful for ensuring that they remain on track (e.g. students with certain special educational needs and / or disabilities). I have shared my Schemes of Work for the term (including all homework tasks) with each set in their Class Notebook in OneNote, so that students know what will be expected of them each week, and so that they are able to prepare ahead if they wish.

\section{Resource creation}

Careful lesson planning and creation or curation of effective resources have long been recognised as vital to the success of online learning (Moreno \& Mayer, 2007). Although originally designed for online curricula in higher education, Mayer's 12 Principles of Multimedia Learning (2001) are an important reference point for those teaching online at all levels, not least because they resonate with key concepts in the areas of Cognitive Load Theory and Dual Coding.

It is all too easy to load up a OneNote page or a PowerPoint slide with far too much text, or entertaining but unhelpful images, and then to talk over this, whilst expecting the students to read and absorb it all at the same time. It is vital for teachers who are creating online content to have a grasp of these issues if they are to maximise the learning opportunities for their students (see Lovell 2020 and Caviglioli 2019); in particular, there is a real danger in online teaching that working memory (which has been shown to be very limited - see Baddeley 2007) will be overloaded. It can be tempting to direct students to the infinite resources on the ancient world which the internet provides, thereby increasing the 'extraneous' cognitive load (that which 'originates from the manner and structure in which the information is presented to students' (Lovell, 2020, p.25)), directing attention away from the intrinsic load (the 'load associated with the core learning taking place' (ibid.)) and making it less likely that they will understand and remember the material. It is equally problematic to ask students to split attention between listening to the teacher and looking at or reading what is on their screen (e.g. when delivering a PowerPoint presentation), or between looking at a diagram or map and reading a text or key which corresponds to it. When we are teaching online, we need to think very carefully about how we sequence new material and how to make our instructions (verbal and written) clearer and simpler than ever so that students are aware of exactly what they need to be doing at each moment in the lesson.

Lovell notes that the crucial thing to bear in mind is the learning objective: it is not the case that 'images are always extraneous to learning' (ibid.). When I read the Arachne story from Ted Hughes' Tales from Ovid with a Year 9 class, I found that having a picture of a loom (an object which is important in the story and which the students were unlikely to have encountered before) aided the students' understanding of the tale (which had indeed been my objective for that lesson). However, I resisted the temptation to include various striking artistic representations of the Arachne story as decoration because I knew that this would potentially distract them from the text and its meaning.

In short: less is more. I have certainly found that over time, my resources have become thinner, the spaces between chunks of text have increased, and I have provided students with longer pauses to read and re-read a passage of text themselves before we enter into a discussion.

\section{Vocabulary and testing}

Cognitive Load Theory has also impacted my thinking about the testing of vocabulary and accidence. It would have been easy (and tempting) to see the lockdowns as periods in which vocabulary and accidence learning and testing were a waste of time, as learning of this kind could not be reliably tested - we simply cannot establish online the sorts of test conditions we would employ in the classroom. However, I believe that pupils need a strong foundation 
of vocabulary and accidence in their long-term memory if they are to get the maximum benefit out of reading Greek and Latin texts and if they are to be able to have the best chance of mastering new constructions when they meet them. I have, therefore, continued to expect students to learn Greek and Latin vocabulary and accidence throughout the periods of remote education. However, it became clear from early on that testing needed to be given some thought.

Relationships grounded in mutual trust and respect are one important way in which we ensure that pupils get the most out of our lessons. I have relied heavily on the importance which my school places on trust within our community, and I had conversations with my classes at the start of each remote-learning period in which I explained the importance of doing tests properly. It has also been important to find a testing app with which I am comfortable, and whilst Quizlet, Kahoot and Memrise all have advantages, I like the simplicity of Microsoft Forms (not least the ability it provides to review the answers in an Excel document if desired).

In terms of types of questions, I have found the following strategies to work well:

a. Using the 'Shuffle Questions' function in Microsoft Forms so that students are given questions in a different order (and thus not able to easily share answers).

b. Using inflected forms as part of the test, e.g. asking them to provide the genitive plural of 'girl' or to translate the nominative singular of animorum.

c. Asking students to manipulate the vocabulary they have learned in a different way, e.g. by providing a synonym or antonym of the verb amo, or by putting it in a sequence (necant, amatis, occidimus, interficio) and asking students to explain which one is the 'odd one out' and why.

d. Asking students to identify an aspect or feature of the word in addition to its meaning, e.g. part of speech, gender, etc.

Other skills which have hitherto been tested under exam conditions have transferred very nicely into extended assessment opportunities. There is undoubtedly something to be gained from asking my Year 13 students to answer an essay question (e.g. 'Cicero uses rhetorical flourishes to hide the weaknesses of his argument'. To what extent is this a fair assessment of In Verrem 2.5?) with all of their resources and over an extended period of time, even if this is not how they would have been or will be assessed in a formal examination. It is preparing them for the next stage of their education and the world of work, and it allows them to do something outside of the confines of their usual examination specifications.

\section{Formative assessment}

Formative assessment has been a vital tool in the teacher's toolkit since well before the publication by Black and Wiliam of Inside the Black Box: Raising Standards Through Classroom Assessment (1998), though that paper did much to raise awareness of its value and impact. I have found formative assessment to be of even greater importance during online teaching. I enjoy the luxury of small class sizes, and thus I usually am able to track student progress informally (through interactions with students in lessons, non-verbal cues and sensing the 'temperature' of the room) as well as formally through tracking data. The former is simply not possible in a remote/online environment, and thus I have found that very simple techniques such as low-stakes quizzes, polls and opinion-gathering through the Teams chat have needed to be employed throughout the course of every lesson so that I can get a sense of how the students are progressing.

Microsoft Forms quizzes have been particularly useful in helping me to determine how pupils are progressing. In order to get data which I can easily and quickly interpret (thus allowing me to see whether or not I need to re-explain a concept before moving on), I have made frequent use of multiple-choice questions, but, as Wiliam and Leahy (2015) note, these questions need to be thought about very carefully in order to ensure that the level of challenge is right and that the teacher is actually finding out what she wants to know. The Quickfire Lite option in Spiral and Whiteboard.fi have provided very useful 'mini whiteboard' equivalents, and this has allowed me to replicate the usefulness of that technique in an online context. The Microsoft Teams chat has been a useful repository for opinions and ideas, but I have found students to be reluctant to contribute once their peers have done so - it does not enjoy the anonymity of some other apps. Mentimeter (which allows a limited number of free presentations and slides) has allowed me to ask students to create word clouds, to rate statements and to vote for one of several options, all of which I have used in my literature teaching as a way of assessing prior knowledge at the start of a lesson or sparking a lively literature discussion (often with a particularly outlandish statement, such as 'Aeneas has no negative qualities. Rate (from $1-5)$ the extent to which you agree').

\section{Flipped Learning}

I have spent many hours over the course of the past year producing short videos for students. Has it been worth it? Yes and no.

On the one hand, I have found that flipped learning has been vital given the reduction in live lesson time which resulted from our new curricular model. Lesson time is precious; it became even more so for us. Asking students to watch a short video in which I take them through some content, or even just to read a chunk of their textbook in preparation for a discussion, has - along with the aid of a short quiz at the start of next lesson to check understanding enabled me to prioritise lesson time for the higher-order skills (particularly analysis, evaluation, and creation - the keys to success in languages and humanities) which appear at the top of Bloom's taxonomy (1956).

I have used videos successfully in other ways. I have found that in-class time can be saved by setting as homework the watching of a video in which I deliver whole-class feedback (e.g. in which I deal with common errors in a translation or suggest strategies for success in an extended GCSE literature response), followed by time for pupil corrections. I have recorded the exposition portions of lessons for students who have been absent due to illness/time differences; this has enabled the students to get ahead in advance of a catch-up session with me. Finally, although my videos are not a possession for all time, I do like the idea that students can pause/ rewind them if they wish, and that they could (theoretically) re-watch some videos as part of their revision.

However, there are some things which need to be taken into consideration before we invest too much time in video creation. First of all, it takes a lot of teacher time: I frequently find myself re-recording even a short video (or spending a while editing it) as a result of a stumble or a mistake. Secondly, it can in essence become a lecture. Long videos in particular run this risk, and I always start a longer video (one which is essentially a full homework task) with a request that students have some paper next 
to them, because they will be asked at various points to pause the video in order to complete an activity. I used this as a way of introducing purpose clauses to a Year 12 Greek set; it allowed them to acquire some basic knowledge of the main ways in which we can construct a purpose clause in Greek and to do a few examples before our first lesson on the topic. In that lesson itself, I was able (after a brief quiz to assess the extent to which they had mastered the basics - and they had mostly all got it) to focus on exceptions to the general rules, and to look at a couple of simple worked examples, before moving straight on to some more complex examples. Time was undoubtedly saved, and the pupils were meeting the more challenging elements of the topic with me on hand to support them.

In short, videos work well but they are costly in terms of teacher time. The sharing of these videos within departments and even across schools could be a good way of getting the maximum value out of them. And whilst I always find it fruitful and rewarding to create my own resources, I feel it important not to ignore that which has already been created; there are some excellent TED-Ed videos on, for example, Augustus, the life of a teenager in Ancient Rome and the Vestal Virgins. The Khan Academy, Massolit and Kings and Generals are excellent sources too, and the next stage in my use of videos in teaching will be a combination of creation and also judicious curation of the material which already exists.

\section{Engagement, accountability and student concentration}

There is evidence from the higher-education sector to suggest that student concentration is impacted negatively by technology (Kraushaar \& Novak, 2010). I do not pretend to have solved this issue, but I have found the following strategies to be helpful during the most recent period of online teaching:

- Greeting students by name at the start of the lesson, using student names throughout, and asking students to repeat instructions back to me.

- Laying out expectations at the start of the lesson with respect to switching off mobile phones and closing redundant browser windows to minimise distractions (as noted above).

- Monitoring student activity during the lesson via live marking of work completed in OneNote, and engaging with students who do not seem to be completing tasks (e.g. by sending them a direct message in the chat) - in effect, this is an online version of classroom circulation.

- Monitoring the work completed by students during asynchronous periods, and following this up with the appropriate tutor / pastoral / academic leader.

- Cold-calling and in general having high expectations of students in terms of the level of contribution expected. Short quizzes (five questions maximum) and opportunities for contribution at regular intervals have been vital for ensuring student engagement.

\section{Breaking through the isolation}

It was clear early on in the pandemic that our students were really missing the interactions which happen outside of lessons, such as those at lunchtimes and breaktimes. These provide opportunities for social chat, support, and also for peer-to-peer teaching and learning: I suspect that my students hear me talking more than is ideal, and that they value the opportunities they get to ask a friend to clarify, re-explain or share ideas. This was all lost as a result of the pandemic and the shift from education as a social experience to one of video-conferencing calls received in isolation. There are a few ways in which we have tried to deal with this:

- Cameras: for safeguarding reasons, some schools have required students to keep cameras off during lessons. We have asked students to keep cameras on (but with clear guidelines about dress code and location), and I have found this to be invaluable in terms of creating a sense of a normalised community / a classroom feel, as well as for maintaining momentum and promoting engagement.

- Breakout rooms and collaboration: breakout rooms have been available in Zoom since before the start of the pandemic in March 2020. They became a feature in Microsoft Teams from the end of 2020 onwards, and thus I made use of them throughout the course of the spring term.

I am in general keen on pair and group work; there are always risks (e.g. some pupils might opt out if the teacher is not sufficiently aware of the dynamics of the class), but many of these can be mitigated by giving careful thought in advance to the composition of the group (focusing in particular on motivation, ability levels and potential pastoral issues). Moreover, I feel that the value of peer-to-peer coaching, and the pastoral gains of creating opportunities to allow students just to chat for a minute or two on completion of a task, have been invaluable during the recent lockdown. I have therefore aimed to incorporate pair and group work into my online lessons in the following ways:

1. 'Think, pair, share'. I have used breakout rooms for brainstorming of higher-order questions after the pupils have had a few moments to come up with their own ideas, particularly with reference to literary texts at GCSE (e.g. 'Who is more heroic in Aeneid 2: Priam or Aeneas?'). The whole-class discussions after such paired interactions have generally been of a high quality.

2. Collaborative presentations, e.g. asking students to create a series of slides to present to their peers. This worked well with my Year 12 Greek set; I divided them into three groups, with each pair/trio working on one of the uses of participles in Greek. They worked on a shared PowerPoint slide in Sharepoint (thus all members of a group were able to access their slide at the same time).

3. The Collaboration Space in OneNote. This has again proved useful in allowing students to collaborate on, e.g. a characterisation mind-mapping exercise (though syncing issues mean that having too many students contributing at once is problematic; XMind is a useful alternative for those interested in mind-mapping exercises).

4. Using breakout rooms for translation; as noted above, I always think carefully in advance about the composition of the pairs in order to ensure that both partners will be gaining from the experience.

5. Pairs in breakout rooms have constructed 8- and 10-mark questions on passages of Latin or Greek for a GCSE literature paper.

The conversations I have heard when I have joined the pupils in their breakout rooms have been, on average, of the same or of a higher quality than those I hear when doing similar activities in the classroom. My sense is that as collaborative working has become harder to facilitate, so the students' appetite for it (and desire to make the most of it) has increased. Moreover, I have found that including a short, 
paired discussion (or other similar activity) at the start of each lesson has been a good way to get all students engaged with the material from the get-go, and in particular to get them talking. The formality of the online platform has, I feel, led to some students taking more of a back seat than usual, and breakout rooms have been one way of trying to encourage these students to speak up in a low-stakes environment.

As with all aspects of online teaching, I have found that these sorts of collaborative ventures have required careful thought and planning; as well as determining group or pair composition in advance, teachers need to prepare highquality resources (e.g. with links to the PowerPoint slides in Sharepoint embedded into a document) so that students can find what they need straight away.

- Audio feedback (NB: this is an example of teacher-to-student interaction, but it serves the same purpose as some of the student-to-student interactions described above): I have frequently left my feedback on an extended piece of work, such as a GCSE Latin 8- or 10-mark literature question, in the form of a 'voice note' (using the 'audio' function in OneNote); I have then asked the students to respond to my feedback with a www/ebi statement ('what went well' and 'even better if'). This serves three purposes:

1. It sets up a very clear feedback dialogue, with students acknowledging, digesting and responding to my feedback.

2. I can say more than I can write and, crucially, tone can be conveyed; this allows me to encourage students even when the things I need to say (or the mark achieved) might lead to disappointment.

3. It breaks through some of the isolation which might otherwise result from 'lone working', something which many students are not used to.

Students have potentially felt quite isolated over the course of the past year, and the pastoral issues which have arisen as a result of the pandemic are only just starting to reveal themselves in full. My hope is that some of the methods described above have helped to ward off or mitigate some of those issues, and thus create an environment which is happier and more conducive to learning (in that order) for students.

\section{Independent work}

Perhaps one of the greatest opportunities provided by this situation has been that students have been able to develop their ability to work independently. Independent work has been particularly fruitful with my sixth-form sets; the students in general already have a lot of the background knowledge needed for the task I am setting them (e.g. a translation, the writing of a prose composition, or the planning of an essay), and a greater understanding than younger pupils of where to go for help should they get stuck. Nevertheless, independent work has had to be well managed in order to be effective, and tasks have needed to be carefully sequenced and scaffolded. When asking students to complete a creative writing task on the basis of the Actaeon myth in Ted Hughes' Tales From Ovid (e.g. 'From the perspective of one of Actaeon's fellow hunters, write a short account of the day's events'), I provided them with approximate timings for each stage of the task (reading; planning; writing), optional support materials (top tips for successful narrative writing; suggested paragraph structure), a clear word limit, instructions on how the work was to be presented (in this case handwritten and uploaded as a photo/ scan, rather than typed), and an indication of what to do if they were having difficulties.

Several students whose organisation is usually poor have benefited greatly from our use of OneNote (which does not allow worksheets to be lost, etc.). Nevertheless, clear instructions, very clear deadlines and advice on what to do if a student is stuck (including times when the teacher might be 'on call') all need to be laid out in advance for remote independent work or homework to be effective.

The remote-learning period has also allowed me to optimise my feedback loops: if a piece of work is set on a Monday but I do not see the class again until the Wednesday, I have in the past not been able to start my assessment of that work until - at earliest - Wednesday evening. I might then see the students again on Friday, when I will provide feedback. The submission of work online has allowed me to ask for earlier submissions and to go through work the very next lesson, should I wish to do so. I have also found it invaluable for longer pieces of work, e.g. sixth-form essays, as I have been able to provide feedback on a draft mid-way through the process.

\section{Handwriting}

Typing is a valuable skill, and it seems likely that many of our students will type for the majority of what they do at the next stage of their education and in the world of work. However, I am concerned about the fact that many of them have done very little handwriting over the course of the past year. Handwriting is an important skill in its own right, and for the moment students will continue to be required to handwrite responses in exam conditions. I have therefore implemented the following strategies in my lessons to ensure that some handwriting is done (whilst paying careful attention to the SEND list to ensure that I don't ask a student to handwrite if they have dispensation to type):

- We are fortunate in that all of our current students (with the exception of those in Year 13) have 'inkable' devices; when students are annotating literary texts or answering short-answer questions, I have asked them to handwrite (i.e. 'ink') directly onto their Microsoft Surface Pro (or, if annotating a text, perhaps to print out and write their notes on a hard copy).

- I have required most exam-style essays to be handwritten on paper, then uploaded into OneNote using a Surface camera or an app (Office Lens/Microsoft Lens). Students have sometimes found this to be rather cumbersome (in terms of the uploading process); however, it has allowed them both to work away from a screen and to practise their handwriting, so I feel that the benefit has outweighed any disadvantages.

That said, I have at times made maximum use of the fact that students are routinely doing a lot of typing, and I have specifically set some non-exam-style essays (broader in context and longer in form) and asked for them to be typed. This has produced qualitatively different responses from those produced under exam conditions.

\section{Continuing Professional Development: colleague-to- colleague mentoring}

CPD has been crucial to the development of teacher expertise in the area of online teaching, and to the maintenance of teacher confidence and wellbeing throughout the lockdowns. Twitter has 
become a prominent vehicle for the sharing of teaching strategies over the course of the past few years, and digitally-literate teachers have made full use of it over the past year; the same is true of blogs and of Facebook groups. One of the key benefits of all this is that it allows teachers to look outside of their schools, subjects and keystage specialisms and to borrow ideas from elsewhere.

However, colleagues who feel less confident in their use of technology are perhaps unlikely to go to Twitter or Facebook for help, at least in the first instance, and I have found that peer mentoring and the learning which comes through friendship between colleagues within and across departments have been vital tools. Roles have been reversed: some very experienced teachers those who feel very much 'in control' when it comes to subject knowledge, pedagogy and classroom management - were at a loss at the start of the pandemic, whereas those with less classroom experience but more technological expertise were able to navigate their way round new resources and methodologies with great ease.

Short videos (ideally 2-3 minutes) in which a colleague showcased a very simple but important skill (e.g. how to share a screen in Teams, or set up permissions to ensure that students could not mute their teacher, or play a YouTube clip with audio through a video-conferencing call, etc.) worked well for our staff at the beginning of the first lockdown, and we have continued to distribute (on average) one per week (or one every two weeks). I feel that in general teachers would rather learn from another teacher than from an Information Technology professional, and thus peer-to-peer support and coaching have been very successful in our school. That said, Microsoft's own resources (and YouTube tutorials produced by various enterprising teachers and others) have been invaluable too, especially for those happy to work through a problem on their own.

At the start of the first lockdown I realised the importance of colleague-to-colleague support, and thus increased the frequency of lunchtime CPD talks to a weekly slot in which a teacher would demonstrate an aspect of practice and then discuss its implementation. Attendance was strong; it is clear that colleagues were missing those staffroom chats from which we all learn so much (and which allow us to make ourselves vulnerable in a safe way), and that they wanted to discuss the week's successes and failures with others and - crucially - find out what was working well.

Over the summer, we sent out a survey in which we asked colleagues to self-assess their level of digital literacy. This ranged from level 1 (digital novice) up to level 4 (digital champion). Colleagues were then placed in inter-departmental groups with others of the same level. Each group was led by a 'digital champion' whose task was to guide the team through a series of tasks differentiated according to their self-assessed level (tasks included: setting up a Microsoft Teams recurring meeting; creating a Forms quiz; setting an assignment on Teams; embedding videos and audio clips into OneNote, etc.). Although we were returning to classroom teaching, we were aware that the pandemic had opened the door to opportunities for an increase in the use of technology in all of our teaching (and in particular in collaboration through the use of applications such as OneNote, SharePoint and Microsoft Teams). We wanted to capitalise on the gains we had made in the summer term whilst also preparing ourselves for another potential lockdown; we therefore wanted to establish a basic level of digital competence amongst our staff body to ensure that all colleagues would feel confident in their ability to deliver a good online lesson should the need arise. The model - peer-to-peer mentoring and coaching, in groups divorced from subject specialisms - allowed the sharing of some best practice before the term had begun; it achieved its aim in terms of raising the general standard of teachers' digital literacy, and proved to be successful in other ways too. I am certain that it helped - in a small way - to improve morale and break down the sense of isolation and at times frustration felt by many, not least the digital novices.

\section{Conclusion}

In January 2021, Ofsted published a report entitled What's working well in remote education (2021b). The Education Endowment Fund (2021) has also recently conducted research with respect to supporting students in remote learning. Reassuringly, I feel that many (if not all) of my own conclusions chime in with the main takeaways from these two reports:

- That engagement is important (and that peer-to-peer learning can be used as part of this).

- That formative assessment within online lessons is vital, as is retrieval practice.

- That independent work can be as valuable as live lessons.

- That 'less is more' in terms of both resource layout and the amount of content likely to be covered during a period of remote learning.

There are certainly aspects of my recent experience which I will take forward into my in-person (and, in the interim, hybrid) teaching. I feel that having a greater number of formative assessment points within each lesson is valuable in and of itself, and I am keen to continue using videos both to flip the learning and also to deliver whole-class feedback as part of a homework activity.

Much of this article is not about classics or classics teaching; it would apply to the teaching of any subject. I make no apology for this, because I feel very strongly that there is so much we need to get right before we even consider the material that we are teaching. We must start by securing access to technology for all, developing and maintaining good relationships with students (grounded in trust and mutual respect), planning lessons carefully, and clarifying aims and objectives with students. Once we've got all of that right, we are ready to enjoy the subjects themselves.

\section{Note}

1 We are a Microsoft School, so our primary online learning applications over the course of the past year have been those provided by the Microsoft 365 Environment (Microsoft Teams, OneNote, Forms, Word, Excel, Stream, etc.), though we started on Skype for Business for videoconferencing.

\section{References}

Baddeley A (2007) Working memory, thought and action. Oxford: Oxford University Press.

Black P and Wiliam D (1998) Inside the Black Box: Raising Standards through Classroom Assessment. Phi Delta Kappan 80.

Bloom B (1956) Taxonomy of Educational Objectives: The Classification of Educational Goals, Handbook 1. London: Longmans.

Caviglioli O (2019) Dual Coding With Teachers. Woodbridge: John Catt Educational Ltd.

Coe R (2015) What Makes Great Teaching? Presentation delivered on 31 October 2015 at the IB World Regional Conference (AEM), Den Haag NL. Available online: https://www.ibo.org/globalassets/events/aem/conferences/2015/ robert-coe.pdf. Accessed 8 May 2021.

Education Endowment Foundation (2021) Best Evidence on Supporting Students to Learn Remotely. Available online: https://educationendowmentfoundation. org.uk/eef-support-for-schools/covid-19-resources/best-evidence-onsupporting-students-to-learnremotely/?utm_source=site\&utm_ 
medium=search\&utm_campaign=site_search\&search_term $=$ evidence $\% 20$ supporting\%20students\%20remotely\#nav-best-evidence-on-supportingstudents-to-learn-remotely. Accessed 8 May 2021.

Kraushaar J and Novak D (2010) Examining the Affects of Student Multitasking with Laptops during the Lecture. Journal of Information Systems Education $21,241-251$.

Lovell O (2020) Sweller's Cognitive Load Theory In Action. Woodbridge: John Catt Educational Ltd.

Mayer R (2001) Multimedia Learning. Cambridge: Cambridge University Press.

Moreno R and Mayer R (2007) Interactive multimodal learning environments. Educational Psychology Review 19, 309-326.

Myatt M (2020) Back on Track: Fewer things, greater depth. Woodbridge: John Catt Educational Ltd.
Ofsted (2021a) Remote education research. Available online: https://www.gov. uk/government/publications/remote-education-research/remote-educationresearch. Accessed 8 May 2021.

Ofsted (2021b) What's working well in remote education. Available online: https://www.gov.uk/government/publications/whats-working-well-inremote-education/whats-working-well-in-remote-education. Accessed 8 May 2021.

The Economist (2020) The Pandemic is Widening Educational Inequality. Available online: https://www.economist.com/graphic-detail/2020/07/27/ the-pandemic-is-widening-educational-inequality. Accessed 8 May 2021.

Wiliam D and Leahy S (2015) Embedding Formative Assessment. Learning Sciences International. 